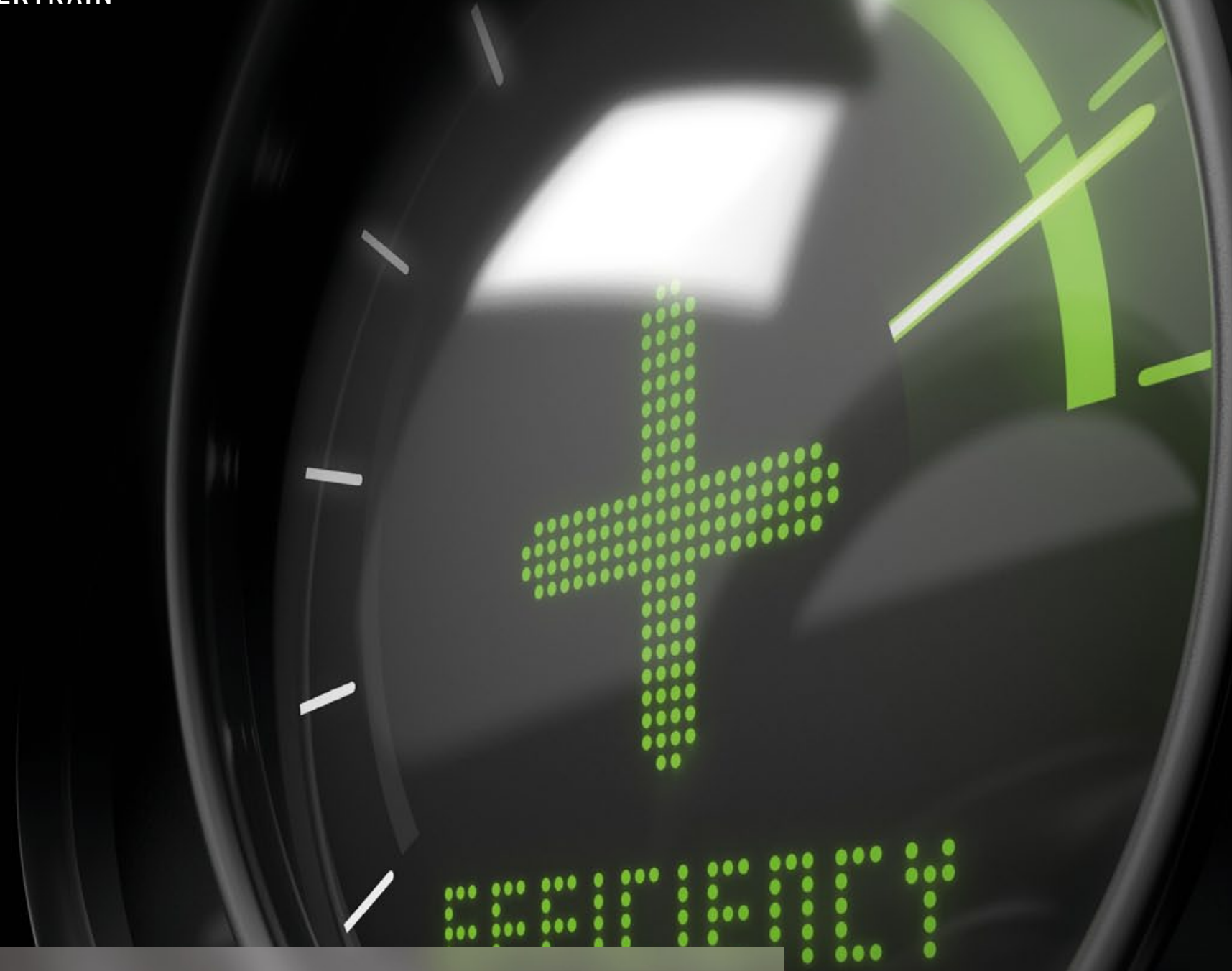

\title{
NEW IDEAS FOR MORE ECONOMIC ENGINES
}

In addition to efficiency gains through downsizing, turbocharging and direct injection, the detailed optimization of all engine components is making an important contribution towards economic and low-emission combustion engines. Friction losses in the engine are particularly important. In the InCarplus project, this is addressed through optimized valve train solutions. Additional potential is being tapped through lightweight solutions with innovative material combinations and functional integration. 